\title{
Development of a Specialized Lathe Chuck for Turning Operations of Cast Iron Rope Wheels
}

\author{
Izabela Miturska ${ }^{1}$, Anna Rudawska ${ }^{1}$, Nadežda Čuboňová ${ }^{2}$, Nataša Náprstkováa \\ ${ }^{1}$ Lublin University of Technology, Faculty of Mechanical Engineering, Nadbystrzycka 36, 20-618 Lublin, PL. \\ E-mail: i.miturska@pollub.pl, a.rudawska@pollub.pl \\ ${ }^{2}$ University of Žilina, Faculty of Mechanical Engineering, Department of Automation and Production Systems, \\ Univerzitna 8215/1, 01026 Žilina, Slovakia. E-mail: nadezda.cubonova@fstroj.uniza.sk \\ 3Jan Evangelista Purkyně University in Ústí nad Labem, Faculty of Mechanical Engineering, Pasteurova 7, 40096 \\ Ústí nad Labem, Czech Republic, E-mail: Natasa.Naprstkova@ujep.cz
}

The use of lathe chucks in machine building companies is the result of a great deal of work and the development of technical thought. Due to the progress and the possibility of increasing efficiency and at the same time relieving people from work that requires a lot of effort, especially physical effort, the use of better and more efficient production methods is a target that should be pursued nowadays. In the manufacturing process, these objectives can be achieved with the use of dedicated equipment. The following work will present an example of a lathe chuck specialized in turning operations. The aim of the work was to use a universal chuck as a base for designing and manufacturing a specialized chuck so that it is possible to mount rope wheels with diameters from 240 to $580 \mathrm{~mm}$. This would eliminate the necessity of time-consuming changeovers. In addition, it is assumed that the handle must meet the conditions imposed by the limited number of tools and the working dimensions of the machine. The machining process itself was also important, where the most advantageous solution was to perform most of the operations in one clamping.

Keywords: Specialized lathe chuck, Turning operations, Rope wheels

\section{Introduction}

During the introduction of a new product into production, it is necessary to perform a series of preparatory works. The main element of these works is the technological preparation of production. It includes: preparation of the technological process, the stage of constructing special equipment, development of work time standards and material consumption standards. Technological instrumentation includes all kinds of workshop aids used in the processing, assembly, inspection or transport of an object $[8,14,19,23]$. This type of assistance includes: handles and instruments for processing, assembly and control, toolholders, gauges, dies, feeders, casting moulds. [4, 16, 24]. It is estimated that about $60-70 \%$ of the production preparation time takes place during the preparation of special equipment, and in exceptional cases it can be as much as $90 \%[2,5]$. Therefore, it is correct to state that the deadline for starting production depends on the time when the technological instrumentation is ready. At the same time, the design of appropriate instrumentation significantly affects the efficiency and quality of the further manufacturing process. In the case of manufacturing processes, where the main operation is machining, the products obtain their shape by removing subsequent layers of material in the process of machining $[12,13,20]$. In this case, productivity can be increased not only by changing cutting parameters, but also by using a special tool or chuck, the use of which will provide, for example, shorter clamping times or greater accuracy. The use of handles and devices not only facilitates the work, but also increases its efficiency. In a situation where high-performance machining methods are increasingly used, the auxiliary time for clamping the workpiece is disproportionately high compared to the machine time [11, 18, 21, 22]. Therefore, it is necessary to take steps towards the development of such structures in order to make this time as short as possible. It should also be noted that the most varied tooling can be found in machining [7, 17]. This is primarily due to the high number of machine tools available on the market and the need to make many parts, often with irregular shapes and high accuracy.

Taking up the task of designing a special tooling for the production of specific products, the starting point is an executive drawing of the final product [6]. This drawing is the basis for drawing a semi-finished product and designing a special tooling, especially in foundry and polymer processing. In machining machining, the basis is also the so-called machining instruction for a particular technological operation [1, 18]. The technologist uses specific symbols to mark 
the location of the support and mounting of the object. A well-planned fixation method is the starting point for the design of the holder for a specific operation. It is important in the construction of the tooling to choose the material from which the elements that make up the finished holder will be made. On this selection depends the operation and durability of the tooling. Carbon and high-alloy tool steels are common materials. Less important parts are made of higher quality carbon steel $[3,9,10]$.

Each special tooling design shall be based primarily on standardized components. This reduces the cost of documentation and tooling. In addition, it is necessary to follow the best practices that can guarantee proper operation and reduce the risk of failure [10].

The aim of this paper was to develop a specialized lathe chuck. The possibilities of using a universal chuck as a base for designing and manufacturing a specialized chuck used during machining of cast iron rope wheels were presented.

\section{Development of a specialized chuck for turning operations}

\subsection{Workpiece description}

The workpiece for which this chuck was developed is the rope wheels in passenger elevator produced by one of the Polish company. Figure 1 shows an example of a cast iron rope wheel with an external diameter of $240 \mathrm{~mm}$. Rope wheels are available in various sizes with diameters ranging from $160 \mathrm{~mm}$ to 700 $\mathrm{mm}$. They are made of materials such as cast iron, steel or polyamide [15]. Depending on the configuration, they have different number of rope grooves with variable diameters.

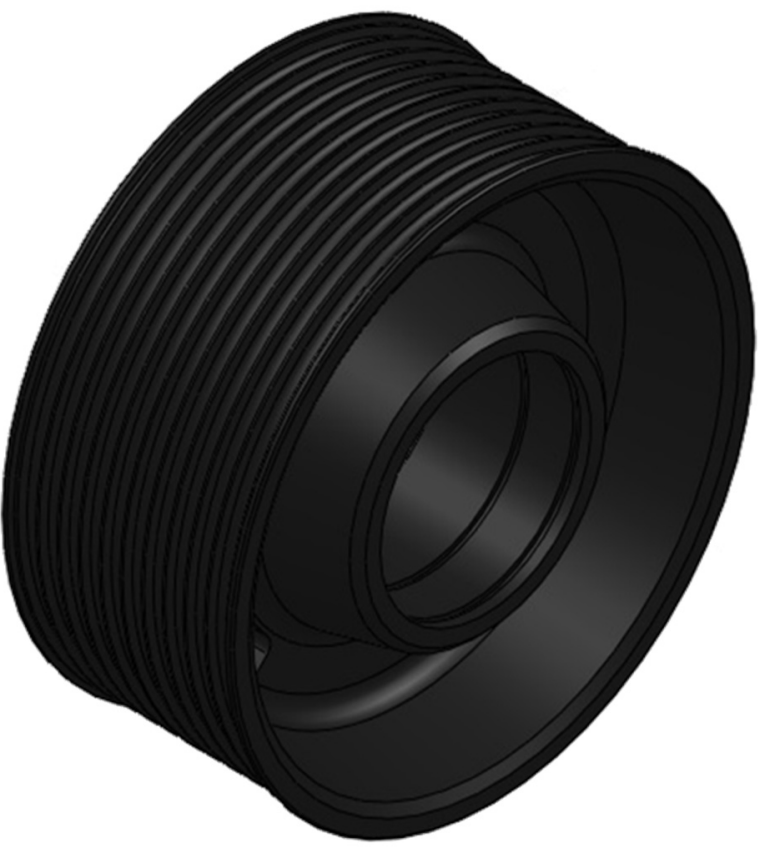

Fig. 1 Cast iron rope wheel with a diameter of $240 \mathrm{~mm}$
The grip which is the subject of this work is designed to be used for turning cast iron wheels with diameters from $240 \mathrm{~mm}$ to $580 \mathrm{~mm}$. Grey cast iron ENGJL-250 according to PN-EN 1561:2012 was used for casting of wheels. The choice of such material is determined by the current needs of the company and its machine park.

\subsection{Workstation description}

The details described above are processed on the Mazak Megaturn Smart 600 lathe centre. It is a vertical lathe designed for making large-size details of significant diameter and large height. The number of elements that can collide with each other has been significantly reduced in comparison with the number of elements in vertical lathes of other manufacturers. The machine has high rigidity and high torque while maintaining high and stable accuracy.

2.3 Issues related to the use of specialized lathe chucks

The development of a specialized lathe chuck was created as a result of changing the machine from a conventional machine tool, on which the discussed rope wheels were previously made, to a numerically controlled machine tool. The second factor was the necessity to increase production efficiency.

Having a certain number and type of tools, it was necessary to make a lathe chuck to allow the possibility of machining rope wheels in order to make the best use of the automatic work. Sandvik's production tools are used to complete the machining of the wheels, as shown in Figure 2. The tools are mounted with a Capto toolholder. Due to the size of the workpieces to be machined and the lack of stock, only three tools with lower clamping can work at the same time: a roughing hole boring bar, a finishing hole boring bar and a groove boring bar. More of these tools would make it impossible to work because the tools would collide with the handle during machining. The other two tools used in machining, i.e. the longitudinal turning and planning tool and the rope groove contouring tool, have a lateral clamping.

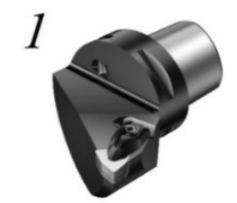

4

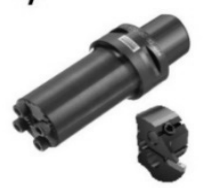

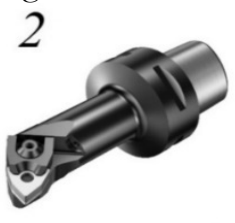

5
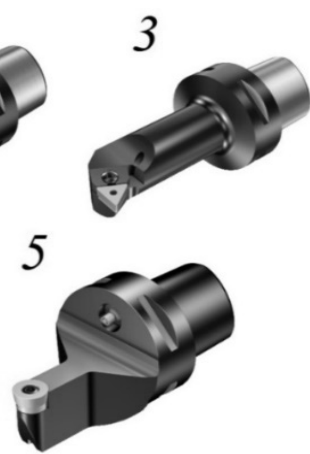

Fig. 2 Tools used for turning rope wheels: 1 - longitudinal planning and turning tool, 2 - roughing tool, 3 - finishing boring tool, 4 -groove boring tool, 5 - tool for contour turning of rope grooves [25] 
During the design of the chuck, the starting point was the analysis of executive drawings and semi-finished parts. Having a drawing of a semi-finished rope wheel presented in Fig. 3, it was possible to design an ergonomic mounting method.
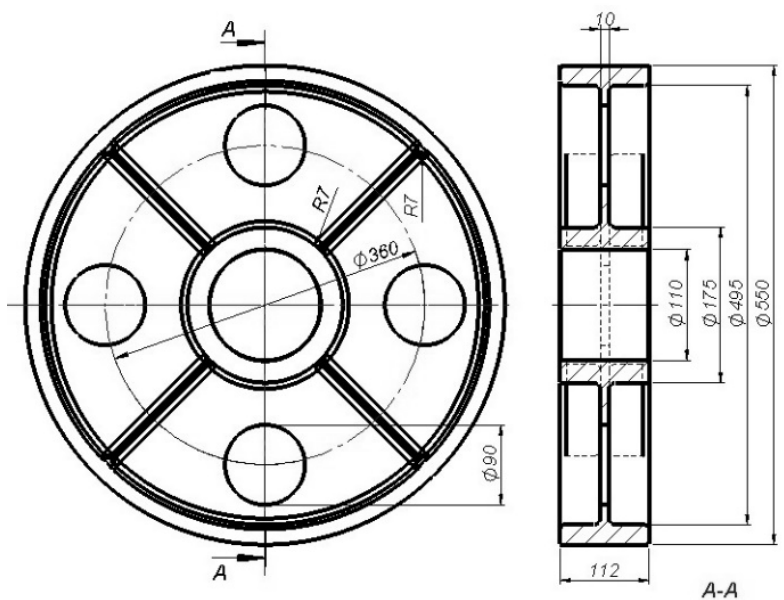

Fig. 3 Semi-finished products drawing of the rope wheel

It was determined that the internal surface of the larger rim will be the retaining surface of the prepared chuck.

\subsection{Structural and technological assumptions}

During the design of grips, it is important to make a proper analysis from the perspective of a workpiece, machine tool and worker. Initial analysis of the possibility of mounting the workpieces proved necessary to use a specialized chuck. As was mentioned earlier, any special tooling design should be based primarily on standardized components. Therefore, a three-jaw pneumatic chuck was used for the development: Kitagawa NV24C15, which is factory applied to the machine.

During the development of the chuck, a modified set of jaws with special overlays enabling the clamping of wheels of different diameters was proposed. During the design of this type of chuck it is necessary to use as many universal solutions as possible and commercial elements, thanks to which it is possible to minimize the costs related to the applied modifications. During the implementation of the work, this assumption was also assumed. Another structural assumption concerns mainly the geometric properties of the chuck. It was assumed that it should be compatible with rope wheels with external diameters from $ø 240$ $\mathrm{mm}$ to $\varnothing 580 \mathrm{~mm}$.

Preparing the required technological assumptions, each considered case should be treated individually and the correct technical parameters should be selected. The following technological assumptions have been included:

- components made of appropriate wear-resistant steel,
- possibility of making parts on a milling machine and a lathe,

- possibility of using standardized components,

- possibility of access to mounting elements,

- the weight of the chuck should not be too high but should be stiff at the same time,

- the construction of the chuck holder should ensure easy chip flow during machining,

- the construction should make it possible to observe the workpieces and take measurements in the holder, without disassembly.

Based on the commercial offers of companies supplying materials, the choice of steel for the production of jaw caps and T-inserts was made. Steel 16MnCr5 according to PN-EN 10277:2018-09 was accepted. It is steel for heat treatment. Elements of this steel type are characterized by high surface resistance to wear. Semi-finished products in the form of bars with dimensions of $\varnothing 110 \mathrm{~mm} \times 130 \mathrm{~mm}$ and $\varnothing 30 \mathrm{~mm} \times 130 \mathrm{~mm}$ were selected.

The machining of the liner and T-bar inserts was planned to be performed on the milling machine, with the exception of the stop surface of the liner, which was planned to be turned on the lathe. In the commercial jaws, it was planned to make a serration and milling of a notch for the clamping of T-bolts fitted to the jaws.

The standard elements used for the preparation of the lathe chuck were hexagon socket cylindrical screws with thread dimensions M12 and M16. In addition, the screw fixing holes were positioned to allow for easy access. Considering the possibility of observing the workpieces, it will be ensured because the mounting will be carried out from the inside of the workpieces.

\subsection{Specialized lathe chuck design}

The design of the specialized handle was made with the use of software supporting Solidworks design. The program has tools that allow you to design structural elements in a three-dimensional workspace.

The design of the chuck involves the following steps:

- model of Kitagawa NV24C15 chuck,

- soft jaw model design,

- creating a model of special caps and T-bar inserts,

- creation of the assembly with standardized elements (fasteners),

- simulation of chuck operation for workpieces with regard to collision. 
Definitely helpful was to create the Kitagawa NV24C15 3D model shown in Fig. 4, based on the available technical drawings of the manufacturer. It was especially important to determine the pitch of the lower jaws of the chuck.

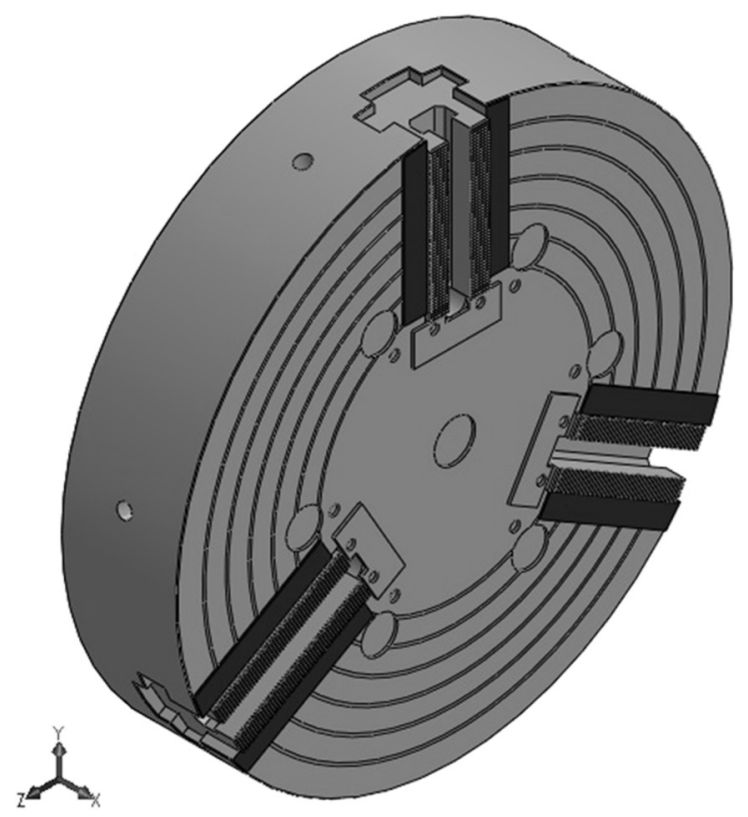

Fig. 4. Kitagawa NV24C15 3D model of the Kitagawa NV24C15 in Solidworks software

The next step was to develop a jaw clamping model with a $3 \mathrm{~mm} \times 60^{\circ}$ serration. Based on the data from the DKT manufacturer, a soft jaw clamping model with catalogue number MKS-M 530-6 was made and modified. Appropriate cuts and serrations were made in order to make it possible to use special T-inserts responsible for mounting the holder, while the serration allows to increase the adjustment of the chuck, which may contribute to its universal character.

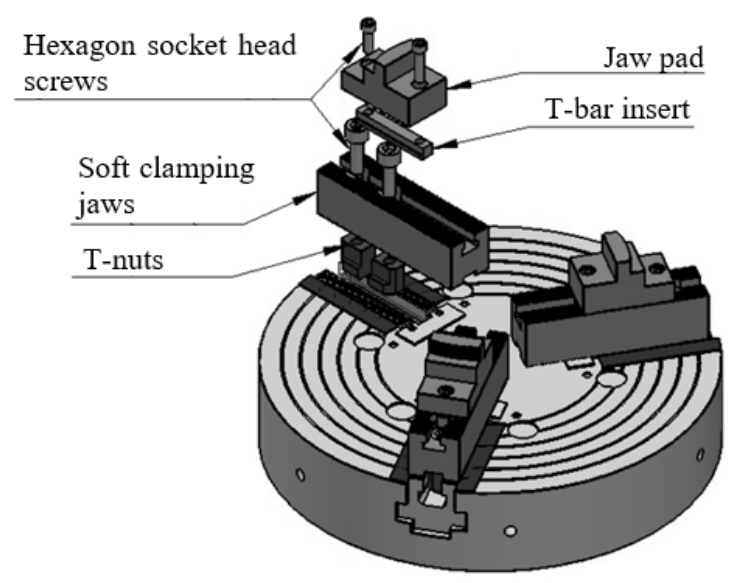

Fig. 5. Construction of a specialized lathe chuck

In the next step, special overlays and T-inserts were made for their fixing. It was important to choose the right dimensions to increase the current jaws, the possibility of using the aforementioned tools and to avoid collision between the jaws and the workpiece during mounting. The described elements were clamped with hexagon socket cylindrical screws according to PN-EN ISO 4762:2006. Soft clamping jaws were clamped with M16x55 screws, the jaw faces were clamped with M12x35 and M12x50 screws. Individual elements of the holder are shown on Fig. 5.

Afterwards, the assembly of the designed elements was created, as shown in Fig. 6.

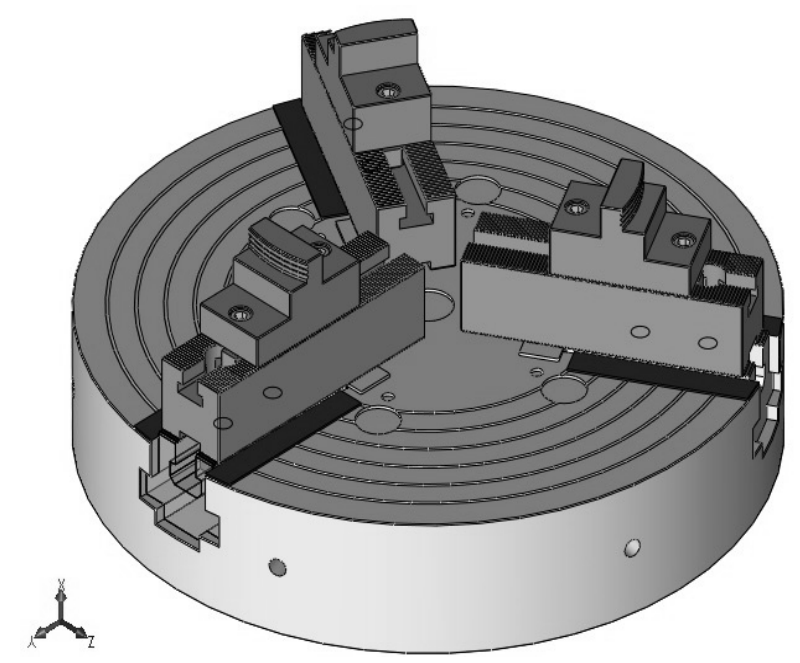

Fig. 6. View of a specialized lathe chuck assembly

It was important to run the assembly in order to run a proper simulation in Solidworks software. A rope wheel model was inserted to simulate the assembly. The first step was to simulate a mount with a rope wheel model with a minimum assumed outer diameter of $\varnothing 240 \mathrm{~mm}$. The diagram in Figure 7 shows the setting of the jaws when the wheel is being machined. There were no collisions, which allows the use of this chuck in the analyzed study.

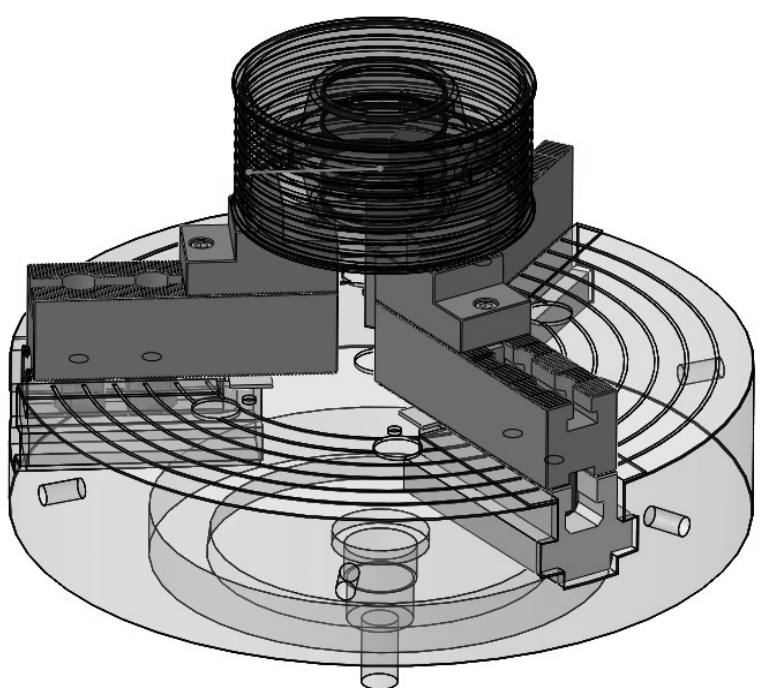

Fig. 7. Schematic diagram of $\varnothing 240 \mathrm{~mm}$ rope wheel mounting

In the next step, a simulation was carried out for the maximum established wheel diameter - $\varnothing 580 \mathrm{~mm}$. 
In this example it is also possible to mount a rope wheels, and fig. 8 shows the position of the clamping jaws.

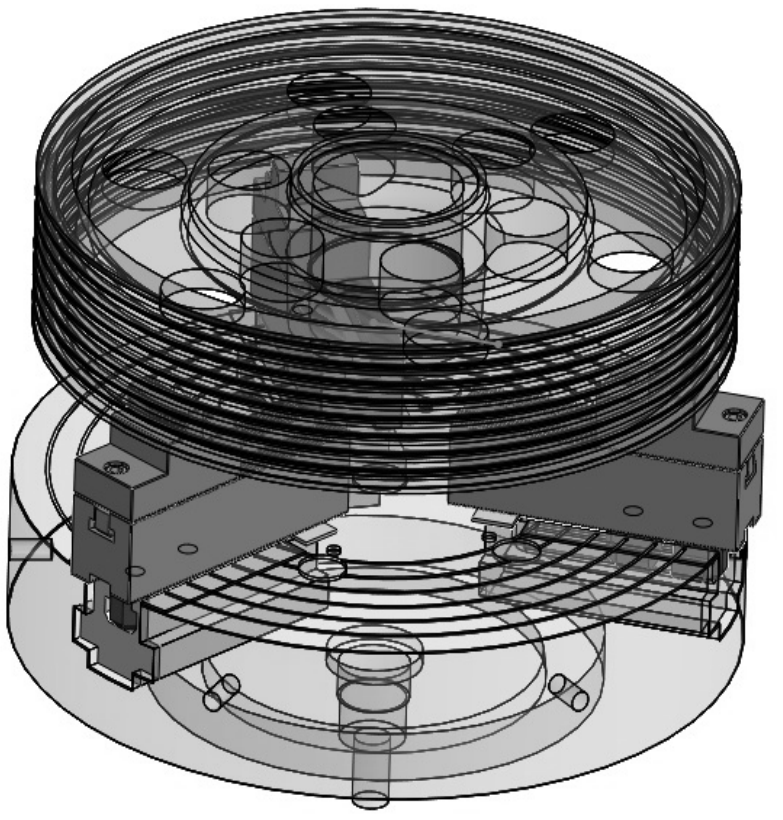

Fig. 8. Schematic diagram of $\varnothing 580 \mathrm{~mm}$ rope wheel mounting

As the last one, a simulation was performed for a wheel with a diameter of $\varnothing 400 \mathrm{~mm}$. Particular attention should be paid to the possibility of a collision of the jaws with the appearing ribs. No collision was also observed for this diameter. As a result of the above simulations, it was concluded that other wheels with diameters ranging from $\varnothing 240 \mathrm{~mm}$ to $\varnothing 580 \mathrm{~mm}$ could be machined.

During the development of the chuck, a method of wheel machining was proposed, which had to be taken into account when preparing the technological process and programming the machining paths for the machining centre. Special attention was paid to the possibility of machining the workpiece without the need for many changes of fastening, because they are time-consuming and require additional work.

Using the tools described above, the following machining sequence had to be created (Fig. 4):

- planning and turning the external surface using tool No. 1,

- groove turning with tool No. 5,

- bores roughing and finishing holes with tools No. 2 and No. 3,

- groove boring with tool No. 4.

The above operations should be carried out in one mounting, the planning of the other side of the wheel should be carried out in universal clamping jaws. During the machining of a determined number of workpieces, the first step is to carry out the machining in the order shown for all workpieces, then to replace the clamping jaws and machining the other side of the wheel.

\subsection{Advantages and limits of the proposed design}

The proposed design has advantages as well as certain limitations. The most important advantages of the handle are:

- possibility to machine workpieces with various dimensions,

- cost-effectiveness in terms of costs and storage,

- improving the ergonomics of the worker's work,

- reduced preparation and completion times,

- adapting to the optimal use of tools.

The use of serration on the clamping jaws allows for a flexible adjustment of the jaw spacing for each individual workpiece, making the chuck a universal chuck. Due to the small pitch of the basic jaws, which is $6 \mathrm{~mm}$, the execution of one set of jaws allows for financial savings associated with the purchase of further elements of equipment to adapt them to the appropriate clamping and no need to prepare storage space for subsequent jaws for wheels of different diameters. Given the existence of unit production, the need to change the jaws would require a worker's effort due to the high weight of the jaws. Thanks to the applied regulation, the preparation of the machine tool for work was reduced significantly, which resulted in reduction of preparation and completion times. Making a specialized chuck allowed the use of selected tools without the need to purchase special tools for a particular machining process.

The limitations of a designed lathe chuck include:

- relatively large mass of clamping jaws,

- necessity of proper setting on the serration,

- possibility of tool collision with the chuck.

Taking into account the dependence of the speed on the mass of the jaws presented by the manufacturers, it was concluded that for the mass of the jaws approx. $11 \mathrm{~kg}$ the possible speed is limited to 1200 rpm [26]. However, due to the fact that the machining is carried out on large cast iron workpieces, the speeds will be much lower. Due to the additional serration, the number of exact positions with the same offset has increased from 3 to 6 , which increases the risk of mistake. When preparing machining programs, special attention should be focused on the positioning of the tools, as well as on the exact size of the clamping jaws in order to avoid collisions. 


\section{Conclusions}

The holders used in machining processes are an important part of the production process. The use of holders is necessary in almost all technological processes. In most cases these holders are used to fix and establish the workpiece, in some cases they have additional auxiliary functions. Holders are used to increase the quality of manufactured parts and the efficiency of the process, reduce the number of scrap and production costs. Optimal selection of the holder allows to increase the machining efficiency. This is done by shortening the auxiliary times associated with the establishment, mounting and unfastening of the workpiece, as well as the possibility of machining with several tools, resulting in a reduction in the main time.

On the basis of the specialized lathe chuck model presented in the paper, the correctness of application of the proposed solution was demonstrated. The analysis of the correctly function of the chuck was carried out by means of simulations. The opportunity to carry out simulations allowed to introduce changes in the design phase, without the need to incur unnecessary costs. It was also helpful to perform an analysis on a machine tool using tools to check the scope of their work, which was an additional possibility to verify the proposed solution, while at the same time it resulted in the avoidance of mistakes. In the paper, the structural, technological and economic assumptions of the presented chuck, which were fully met, were of particular importance. The presented design allowed to process objects of different dimensions by using one tooling. The process of manufacturing rope wheels became more economical from the point of view of the manufacturer and more economical for the workers who took an active part in its realization. In addition, the proposed solution contributed to reducing the preparation and completion times of the process and optimal use of tools.

\section{References}

[1] BARRY, A. (2006). Technological Zones. In: European Journal of Social Theory. Vol. 9, No. 2, pp. 239-253.

[2] BARYLSKI, A. (2017). Quantitative Evaluation of Producibility of Fixture. In: Systemy wspomagania $w$ inzynierii produk.cii - Technology Assessment w ujeciu teoretycznym i praketycznym. Vol. 6, No. 5, pp. 21-32.

[3] ENDLER, I., LEONHARDT, A., SCHEIBE, H.-J., BORN, R. (1996). Interlayers for diamond deposition on tool materials. In: Diamond and Related Materials. Vol. 5, No. 3-5, pp. 299303.
[4] FELD, M. (2002). Machining handles. Scientific and Technical Publishers.

[5] FELD, M. (2000). Mechanical construction technology. Scientific Publishers PWN.

[6] FILLA, R. (2005). Operator and machine models for dynamic simulation of construction machinery. Linköpings universitet.

[7] GRINT, K., WOOLGAR, S. (2013). The Machine at Work: Technology, Work and Organization. Wiley.

[8] HAUSMAN, J.A., LEONARD, G.K. (2003). The Competitive Effects of a New Product Introduction: A Case Study. In: The Journal of Industrial Economics. Vol. 3, No. 50, pp. 237-263.

[9] KALSI, N.S., SEHGAL, R., SHARMA, V.S. (2010). Cryogenic Treatment of Tool Materials: A Review. In: Materials and Manufacturing Processes. Vol. 10, No. 25, pp. 1077-1100.

[10] [KRAMER, B.M. (1987). On Tool Materials for High Speed Machining. In: Journal of Engineering for Industry. Vol. 2, No. 109, pp. 87.

[11] [KRISHNAKUMAR, K., MELKOTE, S.N. (2000). Machining fixture layout optimization using the genetic algorithm. In: International Journal of Machine Tools and Manufacture. Vol. 4, No. 40, pp. 579-598.

[12] KURATA, Y., MERDOL, S.D., ALTINTAS, Y., SUZUKI, N., SHAMOTO, E. (2010). Chatter Stability in Turning and Milling with in Process Identified Process Damping. In. Journal of Advanced Mechanical Design, Systems, and Manufacturing. Vol. 4, No. 6, pp. 1107-1118.

[13] LI, W., KARA, S. (2011). An empirical model for predicting energy consumption of manufacturing processes: a case of turning process. In: Proceedings of the Institution of Mechanical Engineers, Part B: Journal of Engineering Manufacture. Vol.9, No. 225, pp. 1636-1646.

[14] LITVAJ, I., STANCEKOVA, D. (2015). Decision - Making, and Their Relation to The Knowledge Management, Use of Knowledge Management in Decision - Making. In: Procedia Economics and Finance. Vol. 23, pp. 467-472.

[15] LONKWIC, P. (2007). Selected aspects of the operation of cable gearboxes in passenger lifts. In: Dozór Techniczny. Vol. 1, pp. 15-19.

[16] MARTINOV, G.M., OBUHOV, A.I., MARTINOVA, L.I., GRIGORIEV, A.S. (2014). An Approach to Building Specialized CNC Systems for Non-traditional Processes. In: Procedia CIRP. Vol. 14, pp. 511-516. 
[17] NÁPRSTKOVÁ, N., ŠRAMHAUSER, K., CAIS, J., STANČEKOVÁ D. (2018). Using of the Electron Microscope to Evaluate the Tool Wear for a Selected Cutting Insert. In: Manufacturing Technology. No. 18, pp. 635-640.

[18] PETER, H. (2018). Precision machining technology. Cengage Learning.

[19] RUDAWSKA, A. (2016). Production process logistics. Wydawnictwa Komunikacji i Łączności.

[20] SCHEY, J.A. (2000). Introduction to manufacturing processes. McGraw-Hill.

[21] SCHMITZ, T.L., DONALSON, R.R. (2000). Predicting High-Speed Machining Dynamics by Substructure Analysis. CIRP Annals. Vol. 1, No. 49, pp. 303-308.

[22] STANCEKOVA, D., MARTIKAN, P., SVOBODOVA, J., JANOTA, M.,
KRATOCHVIL, J. (2018). Influence of Cutting Parameters on Cylindricity Deviation by Centerless Grinding. In: Manufacturing Technology. No. 18, pp. 674-678.

[23] VIVARELLI, M., PIANTA, M. (2000). The Employment Impact of Innovation: Evidence and policy. Taylor \& Francis.

[24] ZAHAVI, E., TORBILO, V. (2019). Fatigue Design: Life Expectancy of Machine Parts. CRC Press.

[25] https://www.sandvik.coromant.com [access date: 22.11.2019]

[26] Operating Instructions for Megatum Smart Machine Tools. Japonia, Yamazaki Mazak Corporation [access date: 22.11.2019] 